\title{
LA DANZA DURANTE: CONTINUIDAD Y GRACIA DE BERGSON
}

\author{
Felipe Kong Aránguiz \\ Universidad de Chile \\ Felipekaranguiz@gmail.com
}

\begin{abstract}
RESUMEN / ABSTRACT
Este texto parte de una escena, de una situación compleja y singular que expone Bergson al principio de su Ensayo sobre los datos inmediatos de la conciencia. Se trata del párrafo en el que habla sobre el sentimiento estético de la gracia, en relación con la contemplación de un cuerpo danzante. A partir de una lectura atenta de este pasaje podemos repensar el concepto de duración bergsoniano, comprendiendo su dimensión relacional y continua; en otras palabras, su dimensión rítmica. La danza funcionará como una posible imagen mediadora entre estos conceptos.
\end{abstract}

Palabras ClaVE: Bergson, duración, danza, gracia, continuidad, ritmo, relación, cuerpo.

\section{DURATIONAL DANCE: CONTINUITY AND GRACE OF BERGSON}

This text starts from a scene, a singular and complex situation exposed by Bergson at the beginning of his Essay about the immediate data of consciousness. It is the paragraph in which he talks about the aesthetic feeling of grace, in relation with the contemplation of a dancing body. Based on a closereading of this passage we can rethink the bergsonian concept of duration, understanding its relational and continuous dimension: in other words, its rhythmical dimension. Dance will work as a possible mediating image between these concepts.

KEYWORDS: Bergson, duration, dance, grace, continuity, rhythm, relation, body.

$\overline{R M}$ Partimos de una escena sencilla: un filósofo nos expone, en primera persona plural, un encuentro con otro cuerpo que se mueve, con otra duración. Bergson no lo dice explícitamente, pero todo nos hace pensar que este otro está bailando. De este baile se disparan pensamientos que se van interpenetrando en el alma, que van durando a su vez, y que nosotros en este ensayo intentaremos continuar en sus diversas tendencias, siguiendo sus bifurcaciones, a veces inevitablemente forzándolas. Esta escena nos permitirá experimentar, entonces, el uso de la danza como imagen mediadora ${ }^{1}$, a

“-[U]na imagen que es casi materia en tanto se deja todavía ver, y casi espíritu en tanto no se deja tocar-, fantasma que nos acosa mientras damos vueltas alrededor de la doctrina 
medio camino entre la intuición original y la exposición discursiva que en todo caso ella ya anuncia: imagen que nos puede servir para leer a Bergson, pero que sobre todo nos vale por sí misma, en el abanico de impulsos que hace saltar. Porque no se trata de cualquier danza, sino de aquella que se considera en su cruce conceptual con la duración, o más bien con las duraciones. Y la pregunta que nos moverá entonces, la que irá dando sentido a este recorrido es sencillamente: ¿cómo dura una danza?

Los textos de Bergson suelen comenzar haciendo un llamado a experimentar, situándonos en una experiencia común que se va desenvolviendo en varias direcciones. Podemos seguir el recorrido que hace, dejándonos llevar por él; pero también podemos continuar por nuestra cuenta, agradeciéndole por habernos dado ese primer impulso. Así es en Materia y Memoria, con su impresionante despliegue intuitivo de un universo de imágenes; así también es en Ensayo sobre los datos inmediatos de la conciencia (desde ahora: Datos), donde una retahíla de casos singulares de duración nos va sugiriendo una idea de ella. Cada caso se describe en sus variaciones temporales: la esperanza, la alegría, la tristeza, tienen cada una sus momentos cualitativos. Pero también el paso de un estado del alma al otro es duración, y así podemos pensar el texto de Bergson como un solo flujo en el que los saltos de un ejemplo a otro se van dando por micromovimientos que los entrelazan. Por eso antes de ir al pasaje que nos atañe revisaremos su concatenación con los anteriores.

De lo que se trata en aquel primer capítulo es de mostrar cómo los cambios de los estados internos del alma, que habitualmente nos explicamos según aumento o disminución de intensidad, son realmente modificaciones cualitativas: entre uno y otro hay diferencia de naturaleza, no diferencia de grado. El error se debe fundamentalmente al hecho de que para pensar nuestra vida interior solemos usar categorías hechas para el espacio exterior, como la de número. "Es que, cuanto más se baja a las profundidades de la conciencia, menos derecho se tiene a tratar los hechos psicológicos como cosas que se yuxtaponen" (Bergson 1999, pp. 19-20). El primer ejemplo dado es elocuente: la emergencia de un deseo que poco a poco se adueña de toda el alma. No se trata de que el deseo vaya progresivamente ocupando más espacio, siendo más grande, sino que influye sobre más elementos de la vida psíquica, "tiñéndolos" para su favor de distintas formas:

¿No es verdad que os dais cuenta de una pasión profunda, una vez contraída, por el hecho de que los mismos objetos no producen ya en vosotros la misma impresión? Todas vuestras sensaciones, todas vuestras ideas os parecen refrescadas por aquélla; es como una nueva infancia. Experimentamos algo análogo en ciertos

y al que es preciso dirigirse para obtener la señal decisiva, la indicación de la actitud por tomar y del punto desde el cual mirar" (Bergson 2009, p. 129. Traducción personal). 
sueños en que no imaginamos nada que no sea muy ordinario, y a través de los cuales resuena sin embargo no sé qué nota original (Bergson 1999, p. 19).

Las figuras usadas (colorear, refrescar, resonar) nos evocan una relación inextensa con el espacio: elementos como la música o la luz, que llenan un espacio sin "quitar" espacio, sin ocupar un lugar específico en él. Más bien bañan todo lo que tocan. Vemos que no deja (no puede dejar) de haber un lenguaje espacializante y numerizante por parte de Bergson para hablar del alma, pero ya completamente de otra forma a la habitual: no hay un espacio con cosas yuxtapuestas, sino con flujos inmateriales que se cruzan, rodean y salpican; no hay cantidades discretas ni magnitudes medibles, sino multiplicidad de pequeños movimientos. "Cuando se dice que un objeto ocupa un gran lugar en el alma, o incluso que ocupa en ella todo el lugar, ha de entenderse simplemente por ello que su imagen ha modificado el matiz de mil percepciones o recuerdos, y que en ese sentido los penetra, sin hacerse sin embargo ver en ellos" (Bergson 1999, p. 20). "Mil" funciona aquí como metonimia de "incontable", así como "lugar" indica la espacialidad virtual de nuestro pensamiento, nunca identificable con la espacialidad exterior, y que está regida en todo caso por el curso del tiempo.

Con esta base se analizan a continuación los sentimientos de la esperanza, la alegría y la tristeza, definiéndolos en relación con los ritmos y actitudes temporales que les acompañan. Así, la esperanza consiste en un suspenso de la actualización de los posibles, considerándolos a todos igualmente provechosos. De este modo, "la idea del porvenir, preñado de una infinidad de posibles, es, pues, más fecunda que el porvenir mismo" (Bergson 1999, p. 20). La alegría parte describiéndose de una manera similar, como una actitud ante el porvenir; pero luego va moviéndose, llegando a una segunda etapa donde las ideas y sensaciones se aceleran y todo parece fluir con facilidad. Y en tercer lugar, esta aceleración abre paso a una energía nueva, "comparable a un calor o a una luz, y tan nueva, que en ciertos momentos, volviendo sobre nosotros mismos, experimentamos como una nueva sorpresa de ser" (Bergson 1999, p. 21). La tristeza, por su parte, también avanza desde una disposición temporal en la que el porvenir está cerrado y las ideas aparecen empobrecidas, hasta llegar al "placer amargo" de la constatación reiterativa de cada fracaso, una "impresión de aplastamiento" que nos hace imitar la nada.

Comprendemos el procedimiento que lleva a cabo Bergson: los lectores podemos estar más o menos de acuerdo con las exposiciones de la evolución de cada sentimiento, pero de lo que se trata es de experimentar cada uno de ellos en términos de duración, observando sus fases, sus saltos, sus desvíos. Cada uno de estos estados, a su vez, se compone de más estados que tan solo podemos discernir si los padecemos en la vida cotidiana, es decir: si se adhieren a experiencias concretas. Por eso podemos imaginar flujos de alegría o de tristeza distintos a los expuestos, con distintos ritmos o mezclados en distinta medida con otros afectos. Hay que considerar esto para leer el pasaje siguiente, porque la gracia que experimenta Bergson no necesariamente es la que siente cualquiera: no será por ejemplo la que sienten Kleist o Schiller, por dar nombres célebres. Pero tomaremos este texto como principio, en tanto entrecruzamiento único de la danza, la duración, la continuidad y la gracia. Citamos en extenso, destacando algunas partes: 
Los sentimientos estéticos nos ofrecen ejemplos aún más chocantes de esta intervención progresiva de elementos nuevos, visibles en la emoción fundamental, y que parecen acrecentar la magnitud de ella, aunque se limiten a modificar su naturaleza. Consideremos el más simple de ellos, el sentimiento de la gracia. Primero no es más que la percepción de una cierta soltura, de una cierta facilidad en los movimientos exteriores. Y como los movimientos fáciles son aquellos que se preparan unos a otros, terminamos por encontrar una soltura superior en los movimientos que se hacían prever, en las actitudes presentes en que están indicadas y como preformadas las actitudes por venir. Si los movimientos bruscos carecen de gracia es porque cada uno de ellos se basta a sí mismo y no anuncia a los nuevos que van a seguirle. Si la gracia prefiere las curvas a las líneas quebradas, es que la línea curva cambia de dirección en todo momento, pero cada nueva dirección estaba indicada en la que la precedía. La percepción de una facilidad para moverse viene a fundarse aquí, pues, en el placer de parar en cierto modo la marcha del tiempo y de tener el porvenir en el presente. Interviene un tercer elemento cuando los movimientos graciosos obedecen a un ritmo y cuando la música los acompaña. Es que el ritmo y la medida, al permitirnos prever todavía mejor los movimientos del artista, nos hacen creer esta vez que somos nosotros los autores de ellos. Como casi adivinamos la actitud que va a tomar, parece obedecernos cuando la toma en efecto; la regularidad del ritmo establece entre él y nosotros una especie de comunicación, y los retornos periódicos de la medida son como otros tantos hilos invisibles por cuyo medio hacemos que se mueva esta marioneta imaginaria. Incluso si se para un instante, nuestra impaciente mano no puede evitar moverse como para empujarla, como para volver a colocarla en el seno de este movimiento cuyo ritmo se ha convertido en todo nuestro pensamiento y toda nuestra voluntad. Entrará, pues, en el sentimiento de lo gracioso una especie de simpatía física y, analizando el encanto de esta simpatía, veréis que ella os gusta por su afinidad con la simpatía moral, cuya idea os sugiere sutilmente. Este último elemento en que los otros vienen a fundirse después de haberlo anunciado en cierto modo, explica el irresistible atractivo de la gracia: no se comprendería el placer que nos causa si se redujera a una economía de esfuerzo, como pretende Spencer. Pero la verdad es que creemos distinguir en todo lo que es muy gracioso, además de la ligereza que es signo de movilidad, la indicación de un movimiento posible hacia nosotros, de una simpatía virtual o incluso naciente. Es esta simpatía móvil, siempre a punto de darse, lo que es la esencia misma de la gracia superior. Así, las intensidades crecientes del sentimiento estético se resuelven aquí en otros tantos sentimientos diversos, cada uno de los cuales, anunciado ya por el precedente, se hace visible en él y luego lo eclipsa definitivamente. Es este progreso cualitativo el que nosotros interpretamos en el sentido de un cambio de magnitud, porque a nosotros nos gustan las cosas simples y porque nuestro lenguaje está mal hecho para reproducir las sutilezas del análisis psicológico (Bergson 1999, pp. 21-23).

Ya hemos dicho la intención de Bergson: mostrar que el sentimiento estético de la gracia padece variaciones cualitativas en su duración. Podemos distinguir cuatro fases: a) Percepción de una cierta soltura; b) soltura superior, movimientos que se preparan; c) simpatía física, comunicación facilitada por el ritmo; d) simpatía moral, 
la gracia superior, un movimiento posible hacia nosotros. Cada una de estas fases nos incita a problemas distintos que iremos planteando poco a poco. Pero antes de ello, hay que notar una apreciación al pasar que hace el filósofo: la gracia es el sentimiento estético "más simple de todos". Esto contraviene a la concepción clásica de la gracia, que la define como "una especie particular de belleza" (Abbagnano 1980, p. 592) (así aparece en Burke y en Spalleti), y también trasciende a la humanista, representada principalmente por Schiller, donde la gracia se convierte en la belleza de los actos libres del alma (Schiller 1985). En Bergson, la gracia no se deriva de la belleza, sino que emerge por sí sola. De este modo se expresa sutilmente la inversión cinética del pensamiento que lleva a cabo el proyecto bergsoniano: habría más bien que definir la belleza como gracia quieta, porque el movimiento de la gracia no es más que el movimiento incansable del universo.

La primera fase consiste en el encuentro con la gracia, su reconocimiento. Vemos gracia allí donde hay soltura y facilidad, apariencia de poco esfuerzo. El hecho de que los movimientos sean exteriores implica que la gracia es una relación de superficies, es decir: que puede fingirse, construirse. Esto separa a Bergson de otra vertiente de pensamiento respecto a la gracia estética, que la conecta con la gracia teológica. Según esta interpretación, la gracia estética no pertenece al ámbito humano: se recibe como un don desde lo alto, y la falsa gracia es por ello condenable como vanidad. Kleist, en su inclasificable texto "Sobre el teatro de títeres", declara que "[la gracia] aparecerá en la forma más pura en aquel cuerpo humano que poseyere o absolutamente ninguna conciencia o una conciencia infinita, es decir: en el títere o en el dios" (Kleist 1968, p. 157). Bergson será más indulgente. La gracia está en el cuerpo que se aligera, que parece evadir la gravedad con cualesquiera medios. Pero ¿qué pasa con el peso? ¿Puede haber gracia en lo pesado? Hay que establecer, antes que nada, que entre lo pesado y lo ligero hay diferencia de grado, no de naturaleza. Si no hacemos el lazo de la gracia estética con la teológica, nada nos impide aceptar que tratamos con algo relativo y falible, pero plenamente existente: es el cruce de la falta de esfuerzo (como dice Spencer, mencionado más adelante por el propio Bergson) con la soltura, en francés "aisance". La aisance puede traducirse también como "comodidad", incluyendo en ello el sentido económico: es lo que me es cercano y fácil de usar, lo que está a mi disposición, junto a mí (la etimología nos remite al latín adjacentia ${ }^{2}$. Incluso podría

2 Véase http://www.cnrtl.fr/definition/aisance . Agamben comenta, en La comunidad que viene, la palabra "agio", que tiene la misma raíz: "Los poetas provenzales (en cuyas canciones el término aparece por primera vez en las lenguas romances, en la forma de aizi, aizimen), hicieron de agio un terminus technicus de su poética, que designa el lugar mismo del amor. O mejor, no tanto el lugar del amor, cuanto el amor como experiencia del tener-lugar de una singularidad cual sea. En este sentido, agio nombra perfectamente aquel «libre uso 
decirse: la propiedad. Se mueve con gracia aquel que se mueve en lo propio, en su "zona de confort", como dice la psicología popular. Lo pesado y lo ligero son matices de esta cualidad fundamental. Pero la gracia tiene, por sí sola, un sentido económico distinto: es el regalo, lo que se da excluyendo el retorno. Una propiedad que se fuga constantemente de sí, derrochándose sin preocupación, pero siempre manteniendo algo: el don absoluto sería la muerte, la última gracia, el corte discontinuo para llegar a la continuidad total ${ }^{3}$.

La segunda fase complica más a la primera, estableciendo una "soltura superior". Aquí es donde nos empieza a costar más estar de acuerdo con Bergson, donde hay que ajustar y preparar las bifurcaciones. Sentimos que se está acomodando mucho. Es importante que mantengamos presente el campo semántico de aisance, porque la simple "soltura" nos sugiere imágenes que corresponden más bien a otros modos de la gracia. Primero que nada, se nos dice que "los movimientos fáciles son aquellos que se preparan los unos a otros", que se entretejen: los movimientos bruscos, en cambio, se bastan a sí mismos. La línea curva la podemos seguir, vemos cómo va sugiriendo su curso: no así la línea quebrada. Es evidente el modelo que Bergson está siguiendo: la línea curva y los movimientos entretejidos, por un lado, se corresponden con la duración y la continuidad, mientras que la línea quebrada y los movimientos bruscos con el espacio y la discontinuidad. De un lado está la gracia; del otro lado ¿qué está? Bergson responderá unos años más tarde: está la comedia. En su ensayo de 1900, La risa, da una nueva definición de la gracia, más cercana a la clásica, como contrapunto para exponer su teoría de lo cómico. Dice el autor que "algo de la ligereza alada" del alma se traspasa a la materia bruta del cuerpo, haciendo surgir así la gracia. Pero la materia busca a su vez resistir este control, y "atrayendo la actividad de este principio superior, quisiera infundirle su propia inercia y reducirlo a un puro automatismo". El cuerpo-máquina se rebela contra el alma-control, dando paso al ridículo. "Cuando la materia alcanza a condensar exteriormente la vida espiritual, fijar su movimiento, eliminar, en fin, la gracia, consigue en el alma un efecto cómico" (Bergson 1940, p. 29). La risa sería entonces la defensa del alma contra la materia, el castigo de su sublevación. Está claro que este análisis es estrecho, incluso ateniéndonos al esquema dualista que Bergson usa aquí: el alma ríe también por motivos más refinados, sutiles e imprevisibles, en los distintos modos de humor, y el cuerpo ríe por sí solo también, como en la risa soberana de la que habla Bataille ${ }^{4}$. Pero quedémonos en esta franja. ¿En qué consiste la rebelión

de lo propio» que, según la expresión de Hölderlin, es «la tarea más difícil»” (Agamben 1996, p. 21).

Aquí está el fantasma de Bataille, claramente, que volverá a aparecer riendo.

Michel Surya en su biografía de Bataille relata el encuentro fallido de este con Bergson como un punto decisivo para su futuro: teniendo la posibilidad de conocerlo, el aún católico 
mecánica del cuerpo? No es solo en la rigidez, como en los cuerpos muertos, o en la desobediencia, como en los cuerpos cansados y enfermos. El cuerpo maquinal da risa porque cobra vida por sí solo, una vida aparte del alma. Empieza a moverse lo que por derecho no tiene principio de movimiento. Daremos, para ilustrar, una imagen de fantasía. Alguien muere: su fantasma sale de su cuerpo. Pero cuando el espíritu se va alejando y mira para atrás, ve que su cuerpo empieza a agitarse levemente. Se levanta de allí un zombi. Desde el punto de vista del alma, este zombi se mueve torpemente: es una mala máquina, tan desobediente que se mueve sin motor (o sin motivo), como las impresoras viejas. Lo que nos da risa no es el ser-máquina del cuerpo que hace su aparición, sino su exceso: el hecho de que tenga un principio de movimiento propio, o parafraseando a Spinoza, que nadie sepa lo que puede un cuerpo. Dice Didi-Huberman, comentando este texto bergsoniano, que la mecánica cómica del cuerpo "suscita gestos quebrados y no fluidos, dificultades ostensibles, irregularidades rítmicas, movimientos imprevisibles" (Didi-Huberman 2006, p. 96). Ahora bien, si consideramos que el movimiento del cuerpo rebelde es tan movimiento como el del alma, si no creemos que sea una mera resistencia negativa ante un alma que no sabe llevar las riendas de su caballo, hay que reconsiderar la oposición entre gesto gracioso y gesto cómico (en nuestra lengua esta oposición ya está disuelta, porque le llamamos también gracioso a lo que da risa). La gracia marca una continuidad de movimiento, es cierto, pero esta continuidad puede estar hecha de puras discontinuidades, ya sean modeladas por el alma o hechas saltar por la máquina tenaz del cuerpo ${ }^{5}$.

Barthes propone los conceptos de susurro y farfulleo como dos polos de funcionamiento de las máquinas en general, pero centrándose en las máquinas humanas: los acoplamientos eróticos, los ritmos de trabajo, los flujos de lenguaje. El farfulleo consiste fundamentalmente en una anulación por adición: como quien se arrepiente de haber dicho algo y luego para repararlo habla de más, volviendo a arrepentirse. Es "comparable a la serie de sacudidas con las que un motor nos hace entender que no está en condiciones" (Barthes 1987, p. 99). El susurro en cambio es el ruido del silencio, el ruido paradójico de lo que funciona plenamente bien: "el ruido de lo que por

Bataille leyó La risa y le pareció decepcionante. Pero algo se disparó en él que le hizo, por oposición, pensar la risa de un modo más profundo (más allá de lo cómico). "La risa es la fundación; ella revela lo que está en las profundidades de los mundos. Inmediatamente él sintió que era la clave, que uno podría ser poseído por la risa, y que al resolver este enigma lo habría resuelto todo", dice Surya. Así Bataille pasaría por varias fases: primero la risa se identifica con Dios, luego empieza a marcar la distancia lúdica con el mundo en nombre de Dios, y finalmente a marcar esta misma distancia con Dios en nombre de lo bajo, de lo ínfimo, de la muerte. La risa terminaría siendo la disolución de Dios. (Surya 2002, pp. 36-38. Traducción personal).

5 Piénsese en los grandes cómicos del cine y la televisión: Buster Keaton, Los tres chiflados, Chaplin o Chespirito están llenos de secuencias de movimiento gloriosamente torpes, como si la tontería material se pudiera encadenar con la misma perfección que las ideas más sutiles. Las coreografías cómicas no rara vez se entregan a la misma minuciosidad rítmica que las coreografias "serias". 
funcionar a la perfección, no produce ruido; susurrar es dejar oír la misma evaporación del ruido" (Barthes 1987, p. 100). Pero no es la funcionalidad lo que define al susurro, sino el placer. El susurro siempre "implica una comunidad de los cuerpos: en los ruidos del placer que "funciona" no hay voces que se eleven, guíen o se separen; no hay voces que se constituyan; el susurro es el ruido propio del goce plural" (Barthes 1987, p. 100). Hablamos de polos, es decir, umbrales entre los cuales subsiste siempre un mixto. Los susurros y farfulleos de los cuerpos-máquina son los modos que estos tienen para rebelarse ante el alma, para mostrar que ellos mismos son capaces también de movimientos, ya sean continuos o discontinuos.

Bergson habla en esta fase de "el placer de parar en cierto modo la marcha del tiempo y de tener el porvenir en el presente", es decir, una forma de lo que más tarde en Materia y Memoria será la contracción. Este placer que le otorga el movimiento continuo reside en su parte de no-libertad, en su relativa previsibilidad. Pero, ¿no será entonces el farfulleo del cuerpo, el quiebre de la curva, lo que marcaría la libertad? ${ }^{6}$. Podemos reconstituir las causas de un acto libre solo una vez que ya ha pasado, entendiéndolo retroactivamente como posible: "lo posible es el efecto combinado de la realidad una vez aparecida y un dispositivo que la arroja hacia atrás" (Bergson 1972, p. 99). Es como si el viejo Bergson corrigiera al joven, mostrándole que aún no llega a ser tan joven. Podemos considerar que la línea quebrada es un momento, una forma límite de la curva: sobre todo, una forma inesperada. Su discontinuidad solo existiría a través de una continuidad, como cuentas en un collar. Lo que se interrumpe es mi deseo de previsibilidad, mi placer de parar el tiempo, nada más. Y sabemos que este deseo está durando y entretejiéndose con otros deseos, por lo que su frustración no será una cosa particularmente grave. Ni siquiera en nombre de la gracia.

La tercera fase podría entenderse, si nos distraemos, como una simple intensificación de la segunda. Pero la argumentación de Bergson no nos permite, como sabemos, ese avance meramente cuantitativo. Hay un salto de naturaleza entre estas dos fases que es fundamental: hay una forma incipiente de simpatía, "simpatía física". Ya no hablamos de una conciencia que dura y que experimenta el paso de sus estados anímicos en relación con datos exteriores. Ahora hay al menos dos duraciones, la del espectador y la del "artista" (suponemos, como dijimos, que es un bailarín; bien puede ser un artista de circo o un mimo, pero lo que capta Bergson de él es su parte danzante), que entran en simpatía gracias a un tercer elemento: el ritmo.

6 ¿Qué relación habría entre el susurro y la libertad? Los cuerpos susurrantes son gozosos, pero ¿son libres? Más bien habitan el éxtasis, se aproximan momentáneamente a una eternidad prometida. El susurro "sin duda se trata de una utopía”, señala Barthes (1987, p. 101). 
El ritmo no le pertenece al bailarín ni al espectador, es más bien lo que los conecta. Fácilmente podemos visualizar esto si hablamos de un ritmo musical: la música baña a todas las duraciones que toca, y en esta continuidad se abre una relación entre las duraciones tocadas. Pero hay que entender que el ritmo involucra esta exterioridad incluso en formas que parecieran muy pegadas a un cuerpo, como el ritmo de la danza. El ritmo de una danza siempre habita entre quien baila y su entorno, se dirige a una visibilidad virtual a la vez que proviene de ella. Quien baila solo para sí mismo, a su vez, produce esta visibilidad virtual en la forma de escisión o diferencia consigo mismo: se hace múltiple, o más bien, se expone para sí su multiplicidad. Por eso cada duración, a la vez, está llena de ritmos y requiere también de otros ritmos para acoplarse a otras duraciones.

En la obra de Bergson, el concepto de ritmo aparecerá tratado muy indirectamente, casi tomándolo como parte del sentido común, pero en momentos que resultan cruciales. Así, en Materia y Memoria el ritmo es una especie de velocidad cualitativa, como cuando hablamos de "un ritmo más lento". Cada duración se enfrenta a otras duraciones que funcionan a distintos niveles rítmicos: en nuestro caso, el ritmo más rápido de los átomos o el ritmo más lento de las montañas. "La duración vivida por nuestra conciencia es una duración a un ritmo determinado, bien diferente de ese tiempo del que habla el físico y que puede almacenar, en un intervalo dado, un número tan grande como se quiera de fenómenos" (Bergson 2010, p. 228). Así, si somos minuciosos podremos ver que nunca existe una plena correspondencia entre dos duraciones en cuanto tales, pero sí puede haber una franja rítmica que las ponga en relación. Esta idea le servirá a Bergson para poder postular, en Duración y Simultaneidad, "la hipótesis de un tiempo material único y universal" basada en la existencia de una franja rítmica propia de la humanidad: "todas las conciencias humanas son de la misma naturaleza, perciben de la misma manera, caminan en cierto sentido con el mismo paso y viven la misma duración" (Bergson 2004, p. 86). Por tanto, podemos hacer el experimento mental de situar a las personas lo más alejadamente posible en el universo, unas de otras, y atender a la franja rítmica que acontece entre ellos. Así, veremos que no podemos imaginar otra cosa que un "tiempo impersonal" que sucede en el universo mismo si es que eliminamos las conciencias humanas que habíamos puesto, "como otros tantos relevos para el movimiento del pensamiento" (Bergson 2004, p. 87). El ritmo humano (real) no es idéntico al ritmo universal (hipotético), pero lo hace aparecer, lo exige como sustento para la comunicación de las duraciones entre sí.

En Datos, en cambio, la noción de ritmo está ligada particularmente al ámbito artístico. Unas páginas después del análisis de la gracia, Bergson describe el sentimiento de lo bello en diversas artes, recalcando el papel del ritmo como fuente de poder que nos seduce y captura, "haciendo oscilar nuestra atención entre dos puntos fijos" en el caso de la música, o meciendo y adormeciendo nuestra alma, en la poesía, o desacostumbrándonos "de esos cambios incesantes de nuestra vida cotidiana" (Bergson 1999, pp. 23-24), en las regularidades arquitectónicas. El ritmo funciona como un elemento hipnótico y ensoñador, como la trampa que nos hace caer en el plano de la experiencia estética. Así también podemos interpretar el pasaje sobre la gracia, donde el ritmo nos hace creer e imaginar cosas invisibles, para encontrarnos finalmente que "se ha convertido en todo 
nuestro pensamiento y toda nuestra voluntad". Pero también es ya el ritmo mediador, la franja que establece "una especie de comunicación" entre dos duraciones. Y aquí surge una pregunta incómoda. ¿Cómo asegurarnos de que el otro es una duración, y que no es simplemente un engaño generado por la hipnosis del ritmo? Pues el ritmo nos hace creer que somos nosotros los autores de sus movimientos; nos hace suponer que nos obedece cuando cumple nuestra expectativa; nos hace imaginar que sus pulsos son hilos de control de una marioneta. El ritmo es una especie de genio maligno con el que Bergson se vio obligado a pactar posteriormente, para no caer en la locura. Tan ligado a la ficción está el ritmo que incluso en esta obra temprana está sustraído a la naturaleza: "La naturaleza procede por sugestión, como el arte, mas no dispone de ritmo. Lo reemplaza por esa larga camaradería que la comunidad de las influencias padecidas ha creado entre ella y nosotros y que hace que, a la menor indicación de un sentimiento, simpaticemos con ella" (Bergson 1999, p. 24). Una posibilidad es que la constatación de la duración del otro se dé por esta simpatía natural: yo duro y tú duras, porque padecemos las mismas cosas. Después vendría la simpatía rítmica a establecer otro nivel de comunicación. Las dos simpatías en la obra más tardía de Bergson se irán simplificando en una sola, hasta confluir en el ritmo universal de Duración y Simultaneidad: pero por ahora se mantienen separadas. Por ello buscaremos una solución más simple, y postularemos más bien que lo que genera la constatación de la duración del otro es precisamente la gracia, aquel sentimiento de continuidad que veníamos sintiendo hace rato. La percepción de la gracia identifica un continuo en el mundo material que tiene la forma de una duración: movimientos entretejidos y que parecen seguirse unos de otros, interpenetrados, fuera de toda medida. Podría decirse que la gracia es duración exteriorizada al punto de alcanzar una visibilidad convencional. No todos vemos gracia en las mismas cosas, pero sí podemos comprender las convenciones respecto a lo que es gracioso o no, y podemos buscar la gracia en el mundo sin que éste nos la presente, proyectándola en cualquier parte. Porque finalmente sabemos que hay una "razón inexpresable" en las cosas según la cual "no podríamos considerarlas en momentos sucesivos de nuestra duración sin registrar que han cambiado" (Bergson 1999, p. 158). Una cuasi-duración de la materia, que en los libros posteriores irá sustentándose con mayor firmeza ${ }^{7}$.

Ahora bien, esta gracia que permite el reconocimiento de una duración con otra tiene que reunir las problematizaciones que hemos hecho al respecto, en particular

7 Deleuze identifica en El bergsonismo tres hipótesis bergsonianas respecto a la multiplicidad de las duraciones: "pluralismo generalizado, pluralismo restringido, monismo". O el mundo está lleno de duraciones heterogéneas (la tesis de Materia y Memoria), o estas se restringen a los seres vivos (reserva que parece asumir finalmente en Evolución creadora) o una sola duración universal reúne a estas duraciones heterogéneas y les permite comunicarse (Duración y Simultaneidad). Deleuze defenderá esta última hipótesis mostrando su compatibilidad relativa con las otras dos, en nombre del monismo del movimiento que funciona por contracción y dilatación y que produce lo que entendemos por materia (Deleuze 1987, pp. $75 \mathrm{ss}$ ). 
la que tiene que ver con los movimientos discontinuos. Un cuerpo no se mueve discontinuamente más que por un choque de continuos, una polirritmia interna que puede estar trabajada intencionalmente (desde el "alma") o refulgir desde el puro farfulleo del cuerpo rebelde ${ }^{8}$. El cuerpo y el alma bergsonianos se encuentran en el movimiento: y el movimiento, entendido como plano del ser, es la continuidad. Por más discontinuos que sean los movimientos singulares, siempre podrán encontrar en el plano de movimiento su continuidad, por no decir su "ritmo" común. Aunque tenga que ser en el infinito.

\section{V}

Hay puntos punzantes en la tercera fase que no tocamos particularmente, porque los dejaremos para esta cuarta, donde encuentran un despliegue más complejo. Esto se debe a que pasamos desde una simpatía física a una "simpatía moral", y antes de entrar en ella hay que despejar un par de cosas. Estos puntos pueden marcarse por algunas palabras: obediencia, comunicación, casi, todo. La obediencia aparece dos veces: primero, "los movimientos obedecen a un ritmo"; luego, "parece obedecernos cuando la toma en efecto". El papel mediador del ritmo se entrama con una extraña idea de obediencia. Si el ritmo es lo que nos comunica con el bailarín, ¿no estamos más bien los dos sujetos a él por igual? El artista "parece obedecernos", pero a la vez el ritmo se ha apoderado de nosotros. El "parece" es un efecto de distorsión causado por el ritmo, parte de su virtud hipnótica. Por eso hay solo "una especie" de comunicación, porque el ritmo vicia la relación entre duraciones al mismo tiempo que la hace posible, haciéndonos caer en sesgos. Somos obedientes al ritmo porque es el modo en que podemos acceder a la comunicación, pero esta obediencia incluye el dejarnos cautivar por relaciones ilusorias, como la "obediencia" que nos habría de deber el movimiento del otro (asimismo, el bailarín podría tener la ilusión de que el espectador lo obedece a él cuando se queda ahí sentado mirando). Las palabras "casi" y "todo", por su parte, también aparecen en formas extrañas. Por un lado, "casi adivinamos" los movimientos del bailarín; por otro, el ritmo se convierte en "todo nuestro pensamiento y toda nuestra voluntad". El "casi" nos indica una situación en la que solo hay probabilidad, por más baja o alta que ella sea: nunca nos encontramos con el nunca o con el siempre, con la nada o con el todo. Estamos en un eje en el que solo hay diferencias de grado. Bergson

8 Didi-Huberman tiene bellas palabras al respecto, tomando la figura del tartamudeo:

"Toda danza es siempre polirrítmica, como todo poema es siempre polisémico. Por eso el tartamudeo puede ser hipostasiado, no como privación de ritmo, sino como alteración del ritmo, me refiero a su inclinación a la alteridad, la multiplicidad, la complejidad. Un hombre que tartamudea no hace sino más audible la complejidad rítmica que en su cuerpo disocia los latidos del corazón de los movimientos respiratorios, y éstos del parpadeo, etcétera. El bailarín es quien sabrá hacer visible esa complejidad orgánica, hacerla obra, extenderla a todo el espacio, más allá de sí mismo” (Didi-Huberman 2006, p. 97). 
suele mantener precauciones de este tipo, señalando la presencia de "mínimos" y "máximos" que no llegan al absoluto. El espacio absoluto, por ejemplo, es señalado como una abstracción, frente a la existencia real del movimiento de extensión de la materia, que puede llegar a un punto máximo pero sin tocar por ello el límite que la haría transmutar de naturaleza. Pero Bergson sí admite el "todo" en el caso del ritmo. Esto es porque el ritmo nos penetra en la duración, esto es, sin "ocupar" espacio. No hay parte de mi pensamiento y mi voluntad que esté libre del ritmo, pero precisamente porque no podemos hablar de partes en estos niveles. La interpenetración es profunda entre sus elementos, y si un ritmo se anexa a esta duración podrá recorrer todo su presente $\sin$ "quitarle espacio" a nada.

De aquí nos surge la pregunta, entonces: la comunicación entre duraciones, ¿es inmediata o mediada por la obediencia a un ritmo? ¿Es toda o es casi? Bergson dirá que la simpatía moral está "siempre a punto de darse". Es decir, es un casi que se ajusta a la duración: un casi-todo en el tiempo, una inminencia constante que no se actualiza. Por ello es llamada también "simpatía virtual" y "simpatía naciente": hay una disposición simpática puesta en juego en todo momento, naciendo sin culminar. Se trata de "un movimiento hacia nosotros". El cambio cualitativo entre esta fase y la anterior es que en ella la comunicación estaba dada en un sentido actual, presente y subjetivo: el ritmo permitía la puesta en común de las duraciones y disparaba relaciones imaginarias entre ellas, pero sin respuesta. Es necesario que este ritmo modifique su naturaleza, yendo a un plano virtual, no-presente y asubjetivo, para que se pueda establecer la comunicabilidad entre las duraciones. Esto no involucra forzosamente una respuesta actual: una mirada del bailarín al espectador, por ejemplo. Es sencillamente una modificación final dentro del sentimiento de la gracia, el punto en el que este escapa del sujeto y se plantea la posibilidad de habitar en el ritmo mismo, de tal modo que ningún sujeto pueda salir engañado. Recordamos aquí las reflexiones de Agamben sobre el gesto, para las cuales encuentra en la danza el mejor ejemplo: "Si la danza es gesto es, precisamente, porque no consiste en otra cosa que en soportar y exhibir el carácter de medios de los movimientos corporales. El gesto es la exhibición de una medialidad, el hacer visible un medio como tal"'(Agamben 2001, p. 54). El gesto será definido, entonces, como la "comunicación de una comunicabilidad" (Agamben 2001, p. 55): la coronación del gesto gracioso está en este plano virtual que se abre, en casos singulares, hacia el ser del movimiento mismo. Ya no es problema si las dos duraciones son más transparentes o más opacas entre sí, si son heterogéneas o están homogeneizadas por el ritmo común: llegadas a este punto ya están entremezcladas totalmente, asiladas en el movimiento. Así culmina el diálogo de Paul Valéry, El alma y la danza, con una bailarina que cae, abrazando la gravedad, y exclamando: " ¡Asilo, asilo, oh mi asilo, oh Torbellino! Estaba en ti, oh movimiento, más allá de todas las cosas...” (Valéry 1940, p. 55). 
Para terminar, una especulación.

Simone Weil opone, en su insólita teología, la gracia a la gravedad. Su concepto de gracia aúna todos los sentidos de la palabra: el religioso, el estético y el económico, constituyéndose como la única salvación posible ante un mundo dominado por la gravedad. La gracia es siempre divina, pero el Dios de Weil es un Dios inexistente, es el vacío mismo. Así, el universo estaría compuesto de gravedad y vacíos, vacíos que permiten la entrada de la gracia pero que también pueden ser devastados fácilmente por el mecanismo gravitatorio. Quentin Meillassoux, en su lectura sustractiva de Bergson, propone algo similar: todos los flujos tienen sus cortes, sus vacíos internos, como en un "epicureísmo en negativo": "no átomos reales desplazándose de forma azarosa (siguiendo al clinamen) en un vacío infinito, sino "átomos de vacío" desplazándose de forma azarosa en la plenitud infinita de flujos" (Meillassoux 2007, p. 84. Traducción personal). No podemos pensar el universo sino como un continuo de movimiento, pero a la vez no podemos vivir sin esas discontinuidades, sustracciones, desavenencias, farfulleos que constituyen la diferencia del mundo. La danza podría entenderse como el arte de la gracia en general, es decir: aquel que dispone duraciones discontinuas de tal modo que se ritmen juntas, y de esa forma se abran a la continuidad del plano de puro movimiento. Las discontinuidades no por ello desaparecen, ni siquiera se atenúan. Todas las diferencias se mantienen como tales, porque sin ellas nada se movería. Pero también los signos, las medidas, los pensamientos, los sentidos: todos los planos permanecen, solo que la atención se desliza en el plano de la suma continuidad, el plano de planos.

Esta atención no debería entenderse como una atención subjetiva, sino más bien como una triangulación de flujos. Tomamos el hermoso ejemplo de Bergson en Duración y Simultaneidad, para desarmarlo un poco:

Decíamos que es propio de la esencia misma de nuestra atención el poder repartirse sin dividirse. Cuando estamos sentados a orillas de un río, el fluir del agua, el deslizamiento de un barco o el vuelo de un pájaro, el murmullo ininterrumpido de nuestra vida profunda, son para nosotros tres cosas diferentes o una sola, a voluntad. Podemos interiorizar el todo, nos las podemos tener que ver con una percepción única que arrastra, confundidos, los tres flujos en su curso; o podemos dejar exteriores los dos primeros y repartir entonces nuestra atención entre el adentro y el afuera; o, mejor todavía, podemos hacer uno y otro a la vez, uniendo nuestra atención y, sin embargo, separando los tres flujos gracias al singular privilegio que ella posee de ser una y múltiple. Tal es nuestra primera idea de la simultaneidad. Llamamos entonces simultáneos a dos flujos exteriores que ocupan la misma duración porque se insertan uno y otro en la duración de un tercero, el nuestro: esta duración es únicamente la nuestra cuando nuestra conciencia no considera sino a nosotros mismos, pero se vuelve igualmente la de ellos cuando nuestra atención abraza los tres flujos en un único acto indivisible (Bergson 2004, pp. 92-93).

Si consideramos el plano de movimiento como una multiplicidad continua, caótica e inextricable, llamaremos "discontinuidad" a cada jirón de discernibilidad que aparezca 
en él, discontinuidad que de ningún modo anula el continuo. De este múltiple no se discernirán una o dos discontinuidades, sino múltiples: esto es, al menos tres. Pero cada discontinuidad es en sí misma continua, es decir que es un flujo y tiene duración. La forma más sencilla en que las discontinuidades vuelvan al continuo es chocando entre sí, poniéndose en relación simultánea. Bergson lo figura como una conciencia que reúne en sí, a su gusto, los flujos que percibe, considerándose a sí misma un flujo más. Pero realmente lo que necesitamos son solo tres flujos, los cuales se ordenarán según sus franjas de ritmo para establecer una simultaneidad. El río está en cierto ritmo, en otro el pájaro, en otro el barco, y decimos que mientras pasa el río pasa el barco, o mientras pasa el barco pasa el pájaro, o cualquier otra combinación. Ese mientras es la marca de una atención, un ordenamiento de múltiples flujos discontinuos, un montaje de duraciones. Ese mientras, o mejor aún, ese durante, cumple la función de restablecer el continuo a partir de casos singulares. Podemos pensar un durante universal, como Bergson pensó un ritmo o un tiempo; pero requeriría una atención a un grado de complejidad infinito, y somos muy pequeños aún para eso. Tal vez los japoneses percibieron esto mismo cuando inventaron los haiku: Sobre la rama seca / un cuervo se ha posado; / tarde de otoño. El durante no aparece, pero está allí; es la danza de movimientos entre los tres flujos, es su reunión y su despliegue.

\section{Referencias bibliográficas}

Obras de BERGSON

Bergson, Henri (1999), Ensayo sobre los datos inmediatos de la conciencia. Salamanca: Sígueme. (2010), Materia y Memoria. Buenos Aires: Cactus. (1940), La risa. Buenos Aires: Editorial Tor. (2004), Duración y Simultaneidad (a propósito de la teoría de Einstein). Buenos Aires: Del Signo. (2009), La pensée et le mouvant. París: PUF. (1972), El pensamiento y lo moviente. Buenos Aires: La pléyade.

\section{OBRAS DE OTROS AUTORES}

Abbagnano, Nicola (1980), Diccionario de Filosofía. Ciudad de México: Fondo de Cultura Económica.

Agamben, Giorgio (1996), La comunidad que viene. Valencia: Pre-textos. (2001), Medios sin fin. Notas sobre la política. Valencia: Pre-textos.

Barthes, Roland (1987), El susurro del lenguaje. Barcelona: Paidós.

Centre National de Ressources Textuelles et Lexicales, http://www.cnrtl.fr . Deleuze, Gilles (1987), El bergsonismo. Madrid: Cátedra.

Didi-Huberman, Georges (2006), El Bailaor de soledades. Valencia: Pre-textos. 
Kleist, Heinrich von (1968), "Sobre el teatro de títeres", Los románticos alemanes, Selección de Ilse M. de Brugger. Buenos Aires: Centro editor de América Latina.

Meillassoux, Quentin (2007), "Soustraction et Contraction. À proposd >une remarque de Deleuze sur Matière et mémoire", Philosophie 96: 67-93.

Schiller, Friedrich (1985), Sobre la gracia y la dignidad. Sobre poesía ingenua y poesía sentimental. Barcelona: Icaria.

Surya, Michel (2002), Georges Bataille: an intellectual biography. Nueva York: Verso.

Valéry, Paul (1940), El alma y la danza. Eupalinos o el arquitecto. Buenos Aires: Losada. 